\title{
Potassium and magnesium depletion in patients with cirrhosis on maintenance diuretic regimes
}

\author{
P. G. WHEElER, T. SMITH, C. GOLINDANO, A. N. AlAM, S. P. Wilkinson, \\ C. J. EDMONDS, AND ROGER WILLIAMS \\ From the Liver Unit, King's College Hospital and Medical School, Denmark Hill, London, and Radioisotopes \\ Division, Clinical Research Centre, Northwick Park Hospital, Harrow, Middlesex
}

SUMMARY Total body potassium $\left({ }^{40} \mathrm{~K}\right)$ and leucocyte potassium measurements were carried out on 19 patients with stable but decompensated cirrhosis maintained on diuretics for previous ascites. Of 13 patients receiving spironolactone alone none had a total body potassium below the expected lower limit of normal, whereas, of six receiving additional frusemide, two had low values. The results for leucocyte potassium were in agreement and simultaneous measurements of leucocyte magnesium showed a close correlation, those with intracellular potassium depletion also having magnesium depletion. One such patient was treated with magnesium supplements without effect on the potassium, although intracellular magnesium was improved. It is concluded that spironolactone alone is the treatment of choice in the maintenance management of such patients; that additional potassium would be unnecessary; and that additional frusemide should be avoided if possible.

Hypokalaemia has long been recognised as an undesirable development in chronic liver disease and, if induced by diuretics such as chlorothiazides, hepatic encephalopathy may be precipitated (Read et al., 1959). The serum potassium concentration, however, is an insensitive indicator of total body content. Measurement of total exchangeable potassium has provided evidence of potassium depletion, even with normal serum levels, both in uncomplicated cirrhosis occasionally, and more frequently in the presence of oedema and ascites (Aikawa et al., 1953; Nagant de Deuxchaisnes et al., 1961; Casey et al., 1965; Traverso et al., 1966.) There are a number of inaccuracies with this technique, however, and it correlates poorly (Surveyor and Hughes, 1968) with the more recently described and precise method based on estimation of the total body natural isotope $\left({ }^{40} \mathrm{~K}\right)$. Another way of assessing potassium status is by direct measurement of intracellular potassium content using isolated leucocyte preparations (Baron and Ahmed, 1969), and in this paper we describe the use of both measurements to investigate potassium status in patients with advanced chronic liver disease established on long-term diuretic therapy. Leucocyte magnesium was measured simultaneously with leucocyte potassium to determine whether magnesium depletion occurred in

Received for publication 9 February 1977 association with potassium depletion, and in such cases to determine whether improvement in the latter could best be obtained by the addition of oral magnesium supplements as has been observed by other workers (Lim and Jacob, 1972b).

\section{Methods}

The 19 patients investigated comprised seven with alcoholic cirrhosis, four with cryptogenic cirrhosis. four with primary biliary cirrhosis, and four with active chronic hepatitis. In all patients ascites had been present during the previous year, requiring treatment with diuretics which had to be continued to prevent recurrence. Selection of patients was on the grounds of clinical condition, and they were mostly outpatients and fit enough to travel to Northwick Park Hospital by car for measurements of total body potassium. However, all the patients had severe disease with evidence of hepatic decompensation in addition to their former ascites (Table 1). Of those with varices, cases $1,4,5,6,9,12.16,18$, and 19 had bled previously, and since the time of study four have died and one has undergone transplantation.

The diuretic regime at the time of study consisted of a potassium-sparing agent (18 spironolactone, one amiloride), and six of these patients were on additional frusemide. The latter patients were also 
Table 1 Relevant clinical and biochemical data on 19 patients with cirrhosis, at time of investigation

\begin{tabular}{|c|c|c|c|c|c|}
\hline \multirow[t]{2}{*}{ Patients } & \multicolumn{3}{|c|}{ Serum values } & \multirow{2}{*}{$\begin{array}{l}\text { Encepha- } \\
\text { lopathy }\end{array}$} & \multirow{2}{*}{$\begin{array}{l}\text { Osoepha- } \\
\text { geal varice }\end{array}$} \\
\hline & $\begin{array}{l}\text { Bilirubin } \\
(\mathrm{mmol} / \mathrm{l})\end{array}$ & $\begin{array}{l}\text { Alkaline } \\
\text { phosphatase } \\
(I U / l)\end{array}$ & $\begin{array}{l}A S T \\
(I U / l)\end{array}$ & & \\
\hline 1 & 11 & 92 & 62 & + & + \\
\hline 2 & 32 & 141 & 58 & 0 & + \\
\hline 3 & 23 & 61 & 41 & 0 & 0 \\
\hline 4 & 70 & 360 & 59 & 0 & + \\
\hline 5 & 33 & 174 & 74 & 0 & + \\
\hline 6 & 16 & 99 & 57 & + & + \\
\hline 7 & 38 & 240 & 71 & + & 0 \\
\hline 8 & 74 & 345 & 157 & + & 0 \\
\hline 9 & 100 & 212 & 158 & + & + \\
\hline 10 & 56 & 1760 & 123 & 0 & + \\
\hline 11 & 84 & 140 & 80 & + & 0 \\
\hline 12 & 71 & 462 & 80 & + & + \\
\hline 13 & 10 & 85 & 52 & 0 & 0 \\
\hline 14 & 218 & 178 & $7 \overline{7}$ & + & + \\
\hline 15 & 17 & 298 & 44 & 0 & 0 \\
\hline 16 & 113 & 650 & 143 & 0 & + \\
\hline 17 & 31 & 201 & 96 & + & 0 \\
\hline 18 & 35 & 123 & 59 & 0 & + \\
\hline 19 & 104 & 260 & 184 & 0 & + \\
\hline
\end{tabular}

receiving potassium supplements, usually in a dose of $16 \mathrm{mmol}$ per day.

In 15 of the 19 patients leucocyte potassium was measured but this was technically impossible in the other four because of an inadequate white cell yield. Leucocyte magnesium estimation was not carried out on three others because of other technical difficulties with the absorption spectrophotometry.

Total body potassium (TBK) measurements were made using a whole-body counter comprising liquid scintillator detector modules (Smith and Cronquist, 1976). Each patient was measured for 1000 seconds, and a background measurement using a distilled water phantom was also made for the same time both before and after that on the patient. $\mathrm{A} \mathrm{KCl}$ phantom containing $1400 \mathrm{~g} \mathrm{~K}$ was also measured to allow corrections for any minor variations in counting efficiency. The counter had previously been calibrated by the ${ }^{42} \mathrm{~K}$ technique (Burkinshaw, 1967) in groups of male and female subjects covering a wide range in weight. Errors arising from counting statistics and the use of the calibration curve led to a coefficient of variation between $2.8 \%$ and $5.4 \%$. Observed TBK values ( $\mathrm{K}$ obs) were compared with expected normal values ( $K$ exp). In all but two patients, expected values for TBK were calculated using equations expressing the multiple regression of TBK in normal adults on height, weight, and age (Boddy et al., 1972). The expected value has a variation (2 SD from regression) of $\pm 15 \%$ and therefore potassium depletion was taken to be indicated by a $\mathrm{K}$ obs/ $\mathrm{K}$ exp ratio less than 0.85 . The body weights of two of our patients were less than $80 \%$ of those expected for their heights and ages
(Society of Actuaries, 1959) and, therefore, their $\mathrm{K}$ exp values were estimated using a regression equation based on weight only (Edmonds et al., 1975). This has been shown to be more appropriate for underweight individuals than an equation based on both height and weight.

The electrolyte content of leucocytes was estimated after dextran sedimentation and hypo-osmotic lysis of erythrocytes in a specimen of heparinised venous blood, according to the method of Baron and Ahmed (1969). Sodium and potassium concentration is measured by flame photometry and magnesium concentration by atomic absorption spectrophotometry. The normal range for leucocyte potassium was taken as $375 \pm 48 \mathrm{mmol}$ per $\mathrm{kg}$ dry solids ( \pm 2 SD), derived from 37 control subjects, which compares closely with the findings of others(Edmondson et al., 1974). The normal range for magnesium was taken as $34 \pm 9 \mathrm{mmol} / \mathrm{kg}$ dry solids $( \pm 2 \mathrm{SD}$ ), from 13 control subjects.

\section{Results}

All patients were found to have a normal serum potassium $(3.5-5.0 \mathrm{mmol} / \mathrm{l})$ at the time of study, although at some time during the previous year all but two had evidence of hypokalaemia $(<3.5$ $\mathrm{mmol} / \mathrm{l}$ ) and seven of these had had serum potassium levels of less than $3.0 \mathrm{mmol}$ per litre.

In 17 of the 19 patients values for total body potassium $\left({ }^{40} \mathrm{~K}\right)$ were within the normal range. In the remaining two patients, values were reduced. Both these were receiving frusemide in addition to spironolactone, one in a dose of $40 \mathrm{mg}$ daily for almost a year and the other $200 \mathrm{mg}$ daily. The other four patients who were also receiving additional frusemide had values within the normal range, although two had been on a dose of only $40 \mathrm{mg}$ daily for less than three weeks. All patients receiving spironolactone alone had a normal total body potassium, although two of these were close to the lower limit of normal (Fig. 1).

Simultaneous measurement of leucocyte potassium content was carried out on 15 of the 19 patients, including the two with a depleted total body potassium. Values were within the normal range in 12, leaving only three with a leucocyte potassium content indicative of total body depletion. One of these was just below the lower limit of normal. The second was one of the two cases who also showed a depleted total body potassium, the other of these having a normal leucocyte potassium. The third had a reduced leucocyte potassium with a normal total body potassium. Thus, in only two patients out of the 15 in whom both techniques had been employed, was there definite discrepancy between the results. 


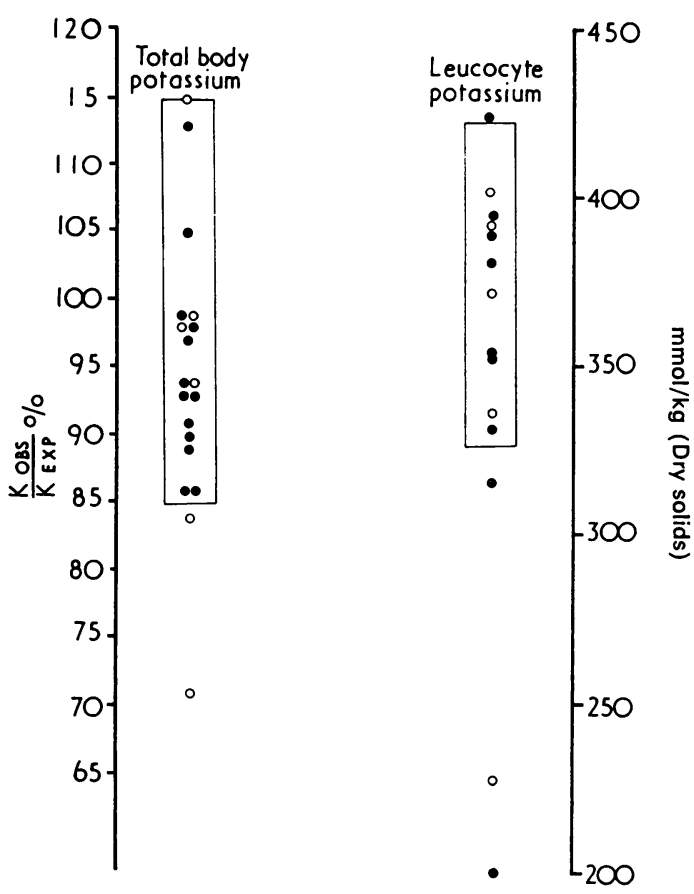

Fig. 1 Values of total body potassium in 19 patients and of leucocyte potassium in 15. spironolactone alone, $\bigcirc$ spironolactone + frusemide. The rectangles signify the limit of the normal values at twice the standard deviation.

The correlation between leucocyte magnesium and potassium content was statistically highly significant $(r=0.84, \mathrm{P}<0.001)$ (Fig. 2). One patient with a slight reduction in leucocyte potassium but a high leucocyte magnesium was found to have been receiving magnesium sulphate by enema until a week before study.

EFFECT OF MAGNESIUM SUPPLEMENTS

The one patient who was potassium depleted on the basis of both total body and leucocyte measurements also had a low leucocyte magnesium, and repeat investigations were carried out after administration of oral magnesium supplements in a dose of $30 \mathrm{mmol}$ daily for one month. During this time she continued on spironolactone $100 \mathrm{mg}$ daily, frusemide $40 \mathrm{mg}$ daily, and potassium $16 \mathrm{mmol}$ daily as before (Table 2). Although the leucocyte magnesium content returned to normal in the space of this month, the total body potassium and leucocyte potassium remained abnormally low. Indeed, there was very close agreement between these two measures of potassium status one month apart (Table 2).

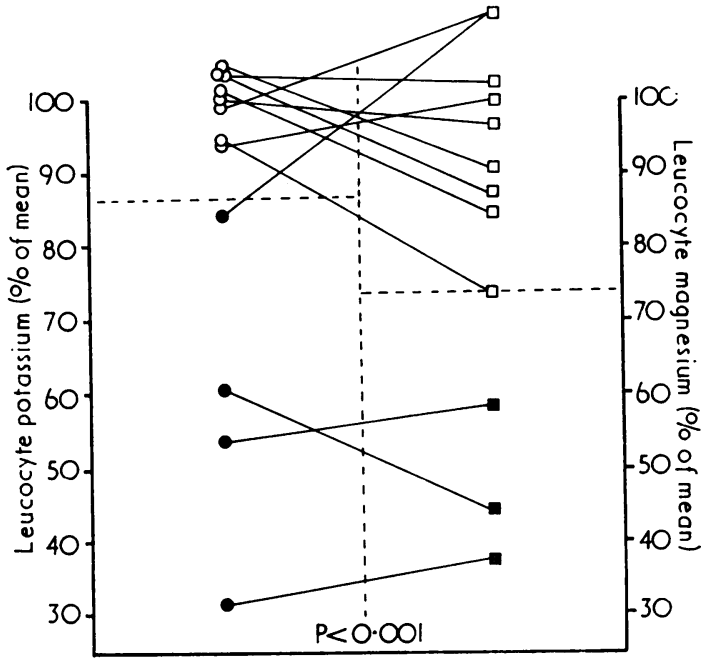

Fig. 2 Simultaneous values of leucocyte potassium and a magnesium content in 12 patients. $\bigcirc$ or $\square$ normal values, or $\square$ subnormal values. Ordinates are percent of normal mean. Horizontal broken lines represent lower limit of normal at twice the standard deviation. Correlation between leucocyte potassium and magnesium is significant at the level of probability, $\mathrm{P}<0.001$

Table 2 Values of potassium and magnesium status in a single patient on spironolactone, frusemide, and slow $K$ before and after one month of oral magnesium supplements

\begin{tabular}{lllll}
\hline $\begin{array}{l}\text { Magnesium } \\
\text { Supplements }\end{array}$ & $\begin{array}{l}\text { T.B.K. } \\
(\text { Kobs mmol) }\end{array}$ & $\begin{array}{l}\text { Leucocyte } \\
\mathrm{K}^{+} \\
(\text {mmol } / \mathrm{kg} \\
\text { dry solids })\end{array}$ & $\begin{array}{l}\text { Leucocyte } \\
\mathrm{Mg}^{++} \\
(\mathrm{mmol} / \mathrm{kg} \\
\text { dry solids })\end{array}$ & $\begin{array}{l}\text { Serum } \mathrm{Mg}^{++} \\
(\mathrm{mmol} / \mathrm{l})\end{array}$ \\
\hline Before & $* 1898$ & $* 228$ & $* 15 \cdot 3$ & 0.68 \\
After & $* 1863$ & $* 262$ & $35 \cdot 0$ & 0.77 \\
\hline
\end{tabular}

*Values reduced below normal range.

\section{Discussion}

The low incidence of potassium depletion found in our patients contrasts with that in a recent study (Soler et al., 1976) in which over $50 \%$ of a series of patients with cirrhosis had a low total body potassium $\left({ }^{40} \mathrm{~K}\right)$. Twelve out of 18 patients on diuretic treatment had low values, whereas only 17 out of 37 patients not receiving diuretics had evidence of potassium depletion. The diuretic regimes differed in that our patients mostly received spironolactone alone, whereas those of Soler et al. were on a potassium-losing diuretic such as frusemide or chlorothiazide in addition to spironolactone. Combinations of potassium-sparing and potassium-losing diuretics still entail a risk of potassium depletion (Yamada and Reynolds, 1970). Even spironolactone 
alone has been said to induce potassium depletion in patients with liver disease (Lévy et al., 1970; Vesin, 1975).

None of our own patients had clinically detectable ascites at the time of study. If some had been present, total body potassium measurements would have been underestimated unless adequate correction was made for the body weight that was higher than expected. In patients with obvious ascites it is likely that there would be a falsely high incidence of depleted values even if correction for ascitic volume is made, as measurement of this volume is difficult, being easily underestimated. This could, in part, account for the large number of potassium depleted patients in some series.

In our group of patients there is agreement between leucocyte potassium and total body potassium in the majority of cases, with only two discrepancies. A correlation has been shown between the leucocyte technique and total exchangeable potassium $\left({ }^{42} \mathrm{~K}\right)$ in animals (Patrick and Bradford, 1972), but in the presence of spironolactone or the metabolic effects of decompensated liver disease, it is not inconceivable that exceptions might occur because of a direct effect on sodium-potassium exchange at the cell membrane, giving a different intracellular result from a total body value.

The close correlation between leucocyte potassium and magnesium content found in our patients is in agreement with the concept of a stable equilibrium of all intracellular cations with relatively fixed ratios between them (Wacker and Parisi, 1968). This confirms observations on skeletal muscle in patients with cirrhosis (Lim and Jacob, 1972a) and on muscle and erythrocytes in the experimental animal (Whang and Welt, 1963). Diuretics may produce cellular magnesium depletion as well as potassium depletion and an improvement in potassium level is said to be greatest when magnesium is added to the oral potassium supplements (Lim and Jacob, 1972b). This was not our experience in the single patient reported in this paper. Further studies were not possible in view of the very low number of such potassium depleted patients.

In a different group of cirrhotic patients with marked sodium retention and accumulation of ascites investigated before diuretic treatment, we found significant reductions in leucocyte potassium content compared with similar patients without ascites (Alam et al., 1976). The same situation is likely to have existed in the present group of patients before treatment.

In conclusion, it would appear that the likelihood of developing potassium depletion is small in patients with cirrhosis and ascites who have undergone initial diuretic treatment, when control can be maintained by spironolactone alone. The need for additional potassium supplements is then not only unnecessary but could be followed by dangerously high blood levels.

We are grateful to Mrs Elizabeth Sindlay of the Department of Chemical Pathology, King's College Hospital for magnesium estimations. We are also grateful to the Clinical Research Group, Smith Kline and French Laboratories, Welwyn Garden City and to Advisory Services (Clinical and General, London) for their generous support and assistance in this study.

\section{References}

Aikawa, J. K., Felts, J. H., and Harrell, G. T. (1953). Alterations in the body potassium content in cirrhosis of the liver. Gastroenterology, 24, 437-443.

Alam, A. N., Wilkinson, S. P., Poston, L., Wheeler, P., Golindano, C., and Williams, R. (1977). Intracellular electrolyte abnormalities in cirrhosis. (Submitted for publication)

Baron, D. N., and Ahmed, S. A. (1969). Intracellular concentrations of water and of the principal electrolytes determined by analysis of isolated human leucocytes. Clinical Science, 37, 205-219.

Boddy, K., King, P. C., Hume, R., and Weyers, E. (1972). The relation of total body potassium to height, weight, and age in normal adults. Journal of Clinical Pathology, 25, 512-517.

Burkinshaw, L. (1967). Measurement of body potassium. Calibration and intercomparison of two whole-body radiation counters. Physics in Medicine and Biology, 12, 477-488.

Casey, T. H., Summerskill, W. H. J., and Orvis, A. L. (1965). Body and serum potassium in liver disease. I. Relationship to hepatic function and associated factors. Gastroenterology, 48, 198-207.

Edmonds, C. J., Jasani, B. M., and Smith, T. (1975). Total body potassium and body fat estimation in relationship to height, sex, age, malnutrition, and obesity. Clinical Science and Molecular Medicine, 48, 431-440.

Edmondson, R. P. S., Thomas, R. D., Hilton, P. J., Patrick, J., and Jones, N. F. (1974). Leucocyte electrolytes in cardiac and non-cardiac patients receiving diuretics. Lancet, 1, 12-14.

Lévy, V. G., Lassale, B., del Corso, A., and Caroli, J. (1970). Effet de l'aldactone sur le stock potassique chez les cirrhotiques ascitiques. Annales de Médecine Interne, 121, 183-190.

Lim, P., and Jacob, E. (1972a). Magnesium deficiency in liver cirrhosis. Quarterly Journal of Medicine, 41, 291-300.

Lim, P., and Jacob, E. (1972b). Magnesium deficiency in patients on long-term diuretic therapy for heart failure. British Medical Journal, 3, 620-622.

Nagant de Deuxchaisnes, C., Busset, R., Collet, R. A., and Mach, R. S. (1961). Exchangeable potassium in wasting, amyotrophy, heart disease, and cirrhosis of the liver. Lancet, 1, 681-687.

Patrick, J., and Bradford, B. (1972). A comparison of leucocyte potassium content with other measurements in potassium-depleted rabbits. Clinical Science, 42, 415-421.

Read, A. E., Laidlaw, J., Haslam, R. M., and Sherlock, S. (1959). Neuropsychiatric complications following chlorothiazide therapy in patients with hepatic cirrhosis: possible relation to hypokalaemia. Clinical Science, 18, 409-423. 
Smith, T., and Cronquist, A. G. (1976). A versatile and economic whole-body counter based on liquid scintillation detector modules. (In preparation.)

Society of Actuaries (1959). Build and Blood Pressure Study, vol. 1 : Society of Actuaries, Chicago.

Soler, N. G., Jain, S., James, H., and Paton, A. (1976). Potassium status of patients with cirrhosis. Gut, 17, 152-157.

Surveyor, I., and Hughes, D. (1968). Discrepancies between whole-body potassium content and exchangeable potassium. Journal of Laboratory and Clinical Medicine, 71, 464-472.

Traverso, H. D., Raynaud, C., Blanchon, P., Roberti, A., Vesin, P., Viguie, R., and Kellershohn, C. (1966). Etude des clearances de l'inuline et du PAH, du débit cardiaque, du $\mathrm{Na}$ et du $\mathrm{K}$ échangeables et des liquides extracellulaires au cours de l'évolution de la cirrhose du foie. Revue Internationale d'Hepatologie, 16, 1377-1398.

Vesin, P. (1975). Potassium metabolism and diuretics administration in liver cirrhosis. Postgraduate Medical Journal, 51, 545-548.

Wacker, W. E. C., and Parisi, A. F. (1968). Magnesium metabolism. New England Journal of Medicine, 278, 658-663 and 712-717.

Whang, R., and Welt, L. G. (1963). Observations in experimental magnesium depletion. Journal of Clinical Investigation, 42, 305-313.

Yamada, S., and Reynolds, T. B. (1970). Amiloride (MK-870) a new antikaluretic diuretic. Gastroenterology, 59, 833-841. 